\title{
The surgical anatomy of the superior gluteal nerve and anatomical radiologic bases of the direct lateral approach to the hip
}

\author{
JC Bos ${ }^{1}$, R Stoeckart ${ }^{2}$, AlJ Klooswijk ${ }^{3}$, B van Linge ${ }^{4}$ and R Bahadoer ${ }^{2}$ \\ 1 Department of Orthopedics, Antonius Ziekenhuis, Bolswarderbaan 1, NL-8600 BA Sneek, The Netherlands \\ 2 Department of Anatomy, Erasmus University of Rotterdam, Postbus 1738, NL-3000 DR Rotterdam, The Netherlands \\ ${ }^{3}$ Department of Radiology, ${ }^{4}$ Department of Orthopedics, Dijkzigt University Hospital, Dr. Molewaterplein 40, NL-3015 GD Rotterdam, \\ The Netherlands
}

Summary. In view of the increasing popularity of the direct lateral approach to the hip joint for hemi- or total hip arthroplasty, the location of the superior gluteal nerve (SGN) was studied. This nerve is in danger when using a transgluteal incision. In 20 embalmed specimens the relation of the SGN to the tip of the greater trochanter (TT) was studied as well as the relation to the iliac crest. For this purpose macroscopy, microscopy and CT were used. In 13 hips a so-called most inferior branch was found at an average of $1 \mathrm{~cm}$ distal to the inferior branch, the main trunk of the nerve. There was substantial variation in the course of both the inferior and the most inferior branch of the SGN. In order to prevent nerve damage, proximal extension of the transgluteal incision should be limited to $3 \mathrm{~cm}$ cranial to TT. Furthermore the incision has to be confined to the distal one third of the distance TT-iliac crest. In tall people extra care should be taken.

Correspondence to : JC Bos
Anatomie chirurgicale du nerf glutéal supérieur et bases anatomo-radiologiques de l'abord latéral direct de la hanche

Résumé. Les recours de plus en plus fréquent à la voie latérale directe de la hanche pour les prothèses totales ou cervico céphaliques nous a conduit à étudier la localisation du nerf glutéal supérieur (SGN) qui est exposé lors de l'incision transglutéale. Les rapports du SGN avec le sommet du grand trochanter (TT) et avec la crête iliaque ont été étudiés sur 20 cadavres embaumés. Nous avons eu recours à l'étude macroscopique, microscopique ainsi qu'au scanner. Dans 13 cas nous avons mis en évidence une branche très inférieure, donc plus distale, située $1 \mathrm{~cm}$ en moyenne en dessous de la branche inférieure habituelle de bifurcation du tronc principal. Il existait des variations importantes dans les trajets de ces deux branches inférieures. Afin de prévenir une lésion chirurgicale du nerf, l'incision transglutéale ne doit pas aller au delà de $3 \mathrm{~cm}$ du sommet du grand trochanter, de plus l'incision doit être confinée en dessous du tiers distal de la ligne joignant le grand trochanter à la crête iliaque.

Key words: Surgical approach Cadaveric studies - Dissection Gluteus medius muscle - Superior gluteal nerve

In operative approaches to the hip joint preservation of hip abductor function is of utmost importance. Otherwise the postoperative gait pattern will be disturbed. However, during the access to the hip the gluteus medius muscle constitutes a distinct obstacle. It can be traversed by the anterolateral, the posterolateral or the transgluteal approach. In the direct lateral approach the muscle is divided longitudinally in the direction of its fibers. This approach, first described by Bauer in 1979 [3] and later modified by others [7, 12], enjoys an increasing popularity because of the excellent exposure of the hip joint. The transgluteal incision is extended distally along the 


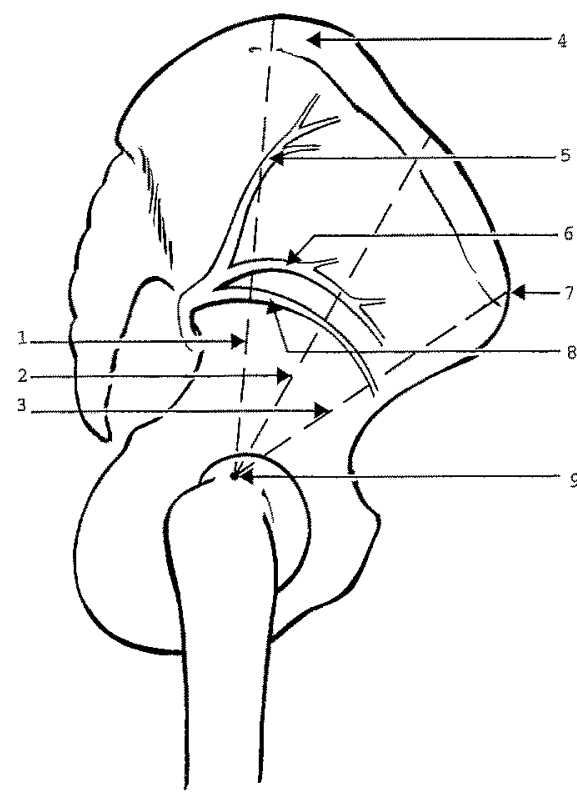

Fig. 1

Lateral view of the right hip with course of superior gluteal $n$. in relation to the tip of the greater trochanter $(9)$ and the iliac crest (4). The midlateral line ( 1 ) is vertical, the incision line (2) follows the direction of the muscle fibers, the spinal line (3) runs to the anterior superior iliac spine (7). The superior gluteal $\mathrm{n}$. divides into a superior branch (5), an inferior branch (6) and a most inferior branch (8)

Vue latérale d'une hanche droite montrant le trajet du n. glutéal supérieur en relation avec le sommet du grand trochanter (9) et la crête iliaque (4) La ligne la plus postérieure est verticale $(l)$, la

ligne d'incision (2) suit la direction des fibres musculaires, la ligne antérieure (3) se dirige en direction de l'épine iliaque antéro supérieure (7) Le n. glutéal supérieur se divise en une branche supérieure (5) et inférieure (6) et branche inférieure supplémentaire ( 8 )

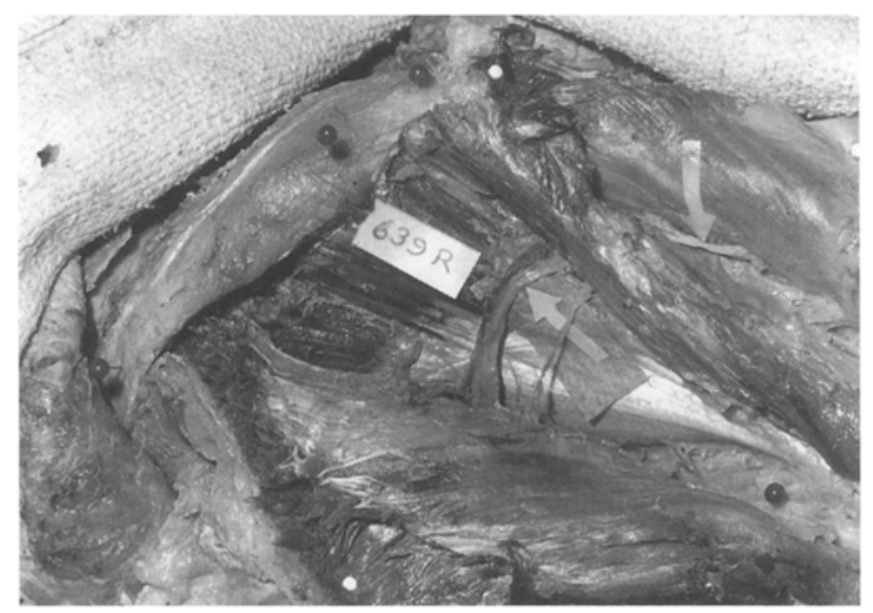

Fig. 2

Specimen 639R (right hip, lateral view) shows the inferior branch of the SGN (lower straight arrow) with the most inferior branch about $1 \mathrm{~cm}$ distal to it. The origin of the gluteus medius muscle has been detached from the outer edge of the iliac crest. The upper curved arrow indicates the terminal branch of the SGN to the tensor muscle. The black pin's head at right is locam ted at the tip of the greater trochanter. The virtual lines between this pin's head and the other 3 black pin's hears indicate from above to below the spinal, incision and midlateral line

Le spécimen $639 \mathrm{R}$ (hanche droite, vue latérale) montre la branche inférieure du n. glutéal supérieur (grosse flêche inférieure) avec une branche inférieure supplémentaire séparée de $1 \mathrm{~cm}$ vers le bas. L'origine du m. moyen fessier a été désinsérée du bord latéral de la crête iliaque. La flèche supérieure courbée montre des branches terminales du nerf glutéal supérieur en direction du $\mathrm{m}$. tenseur du fascia lata. La tête de broche noire à droite est localisée au sommet du grand trochanter. Les lignes virtuelles tracées entre cette flèche et les 3 autres broches représentent de haut en bas la ligne antérieure vers l'épine, la ligne d'incision et la ligne verticale postérieure fibers of the vastus lateralis muscle. The anterior part of both muscles, together with their common tendoperiosteal aponeurosis on the greater trochanter, is dissected free and moved anteriorly as a so-called gluteal bucket-handle flap. The approach is based on the anatomic and functional continuity of both muscles, first described by McFarland and Osborne in 1954 [9].

During exposure there is a risk of damaging the inferior branch of the superior gluteal nerve, with as potential consequence the denervation of the anterior part of the gluteus medius muscle and the tensor fasciae latae muscle. The nerve supply of the tensor by the terminal part of the inferior branch of the superior gluteal nerve is also in danger during the anterolateral approach. This approach uses the interval between the gluteus medius and tensor muscles. Theoretically the nerve supply of the abductor muscles is not in danger during the posterolateral approach. In practice, however, gluteal nerve damage is frequently seen [1].

Because of the controversies in the literature on the course of the superior gluteal nerve and the risk of damaging it, twenty adult cadaveric hip joints were dissected. The location of the most inferior branch of the superior gluteal nerve was studied in relation to the tip of the greater trochanter and the pelvic brim.

Innervation of the tensor fasciae latae muscle by the femoral nerve, as described by Spalteholz [13], might have its bearing on the surgical approach to the hip. Therefore this possibility was additionally studied.

\section{Material and methods}

Careful anatomical dissection was carried out on both hips of 10 specimens, in which no scars were seen from former hip surgery. The specimens concerned 5 men and 5 women 
Table 1. Measurements on the course of the SGN

Mesures effectuées sur le nerf glutéal supérieur

\begin{tabular}{lccc}
\hline & Midlateral line & Incision line & Spinal line \\
\hline $\begin{array}{l}\text { TT-MIB average } \\
\text { range }\end{array}$ & 4.9 & 4.7 & 4.7 \\
TT-IB average & $3.8-6.3$ & $3.3-6.1$ & $3.3-5.9$ \\
range & 5.8 & 5.7 & 5.3 \\
TT-IC average & $4.1-6.9$ & $4.0-7.3$ & $4.0-6.3$ \\
range & 12.3 & 10.4 & 9.4 \\
TT-MIB as \% of TT-IC & $10.5-14.2$ & $8.7-12.2$ & $8.0-11.0$ \\
range & 39.9 & 45.0 & 49.1 \\
TT-IB as \% of TT-IC & $31.7-51.3$ & $32.1-61.1$ & $32.7-71.1$ \\
range & 47.2 & 55.1 & 54.9 \\
\hline
\end{tabular}

Distance in $\mathrm{cm} . T T$, tip of greater trochanter; $S G N$, superior gluteal nerve; $M I B$, most inferior branch of $\mathrm{SGN} ; I B$, inferior branch of $\mathrm{SGN} ; I C$, iliac crest

Distance en $\mathrm{cm}$. $T T$, sommet du grand trochanter; $S G N$, nerf glutéal supérieur; $M I B$, branche inférieure supplémentaire du nerf glutéal supérieur; $I B$, branche inférieure du nerf glutéal supérieur; $I C$, crête iliaque

with a mean age of 82.1 years (range 65-91) and a mean height of $1.70 \mathrm{~m}$ (range 1.55-1.93). The bodies were embalmed by vascular perfusion with a medium containing $2.2 \%$ formaldehyde. With the body fixed in lateral position, the hip joint was approached following the technique of the direct lateral approach. A longitudinal incision was made, centered over the middle of the projection of the greater trochanter through skin, subcutaneous tissue and fascia lata. The transgluteal incision divided the gluteus medius and vastus lateralis muscles longitudinally in the direction of their fibers. The part situated in front of the incision was developped and retracted anteriorly together with its fibro-tendinous junction.

With the tip of the greater trochanter (TT) as reference, three lines were drawn (Fig. 1). On these lines (midlateral, incision and spinal line) the distances were measured between TT and the iliac crest, the inferior (IB) and the most inferior branch (MIB) of the superior gluteal nerve (SGN).

For better visualisation of the SGN, the origin of the gluteus medius muscle was detached from the outer edge of the iliac crest. The distribution of the branches of the SGN was recorded by a drawing and by photography (Fig. 2). The terminal branch to the tensor fasciae latae muscle was searched and recorded as well. In all cases the femoral nerve was dissected in order to discover a possible branch to the tensor. Finally a biopsy was taken at the incision line from the IB and MIB of the SGN, as well as from the terminal branch just before its entrance into the tensor muscle. The diameter of these branches was measured and the number of axons microscopically assessed.

For the radiological examination, CT was used. For this purpose of one cadaver was marked by means of an iron wire. The wire folthe MIB of the left and right SGN lowed the nerve from its origin above the piriformis muscle to its point of entry into the tensor muscle. A CT-scan was made of this pelvis, followed by three dimensional reconstructions.

\section{Results}

The course of the SGN was studied anterior to the midlateral line. The superior branch of the SGN supplied the gluteus minimus muscle in all hips, in 2 of them the gluteus medius muscle as well. The inferior branch supplied the gluteus medius muscle in all hips, in 6 of them via two branches. In 8 hips the inferior branch supplied the gluteus minimus muscle as well. In all limbs the $S G N$ showed a spray-pattern type of distribution, i.e. the nerve divides within 1 or 2 $\mathrm{cm}$ of the superior border of the piriformis muscle into branches fanning out along the intermuscular plane between the gluteus medius and minimus muscles [8]. In none of the 20 limbs branches from the femoral nerve to the tensor were found.

In 7 hips the inferior branch represented the MIB of the SGN. In the remaining hips a separate most inferior branch was present. The distance between TT and the MIB averaged $4.9 \mathrm{~cm}$ on the midlateral, $4.7 \mathrm{~cm}$ on the incision and $4.7 \mathrm{~cm}$ on the spinal line (Table 1). On the incision line the distance ranged from 3.3 to $6.1 \mathrm{~cm}$, only in 5 hips approaching TT within $4 \mathrm{~cm}$. Here, the IB never approached within 4 $\mathrm{cm}$; the distance between IB and MIB averaged $1 \mathrm{~cm}$ (Fig. 1).

The course of the IB and MIB in relation to the pelvis is rather variable. On the incision line the distance TT-MIB averaged $45 \%$ of TTIC with a range of $32.1-61.1 \%$. The IB never reached the distal one third of the distance TT-IC, the MIB only in one hip. In 15 hips the IB remained in the proximal half of that distance. 

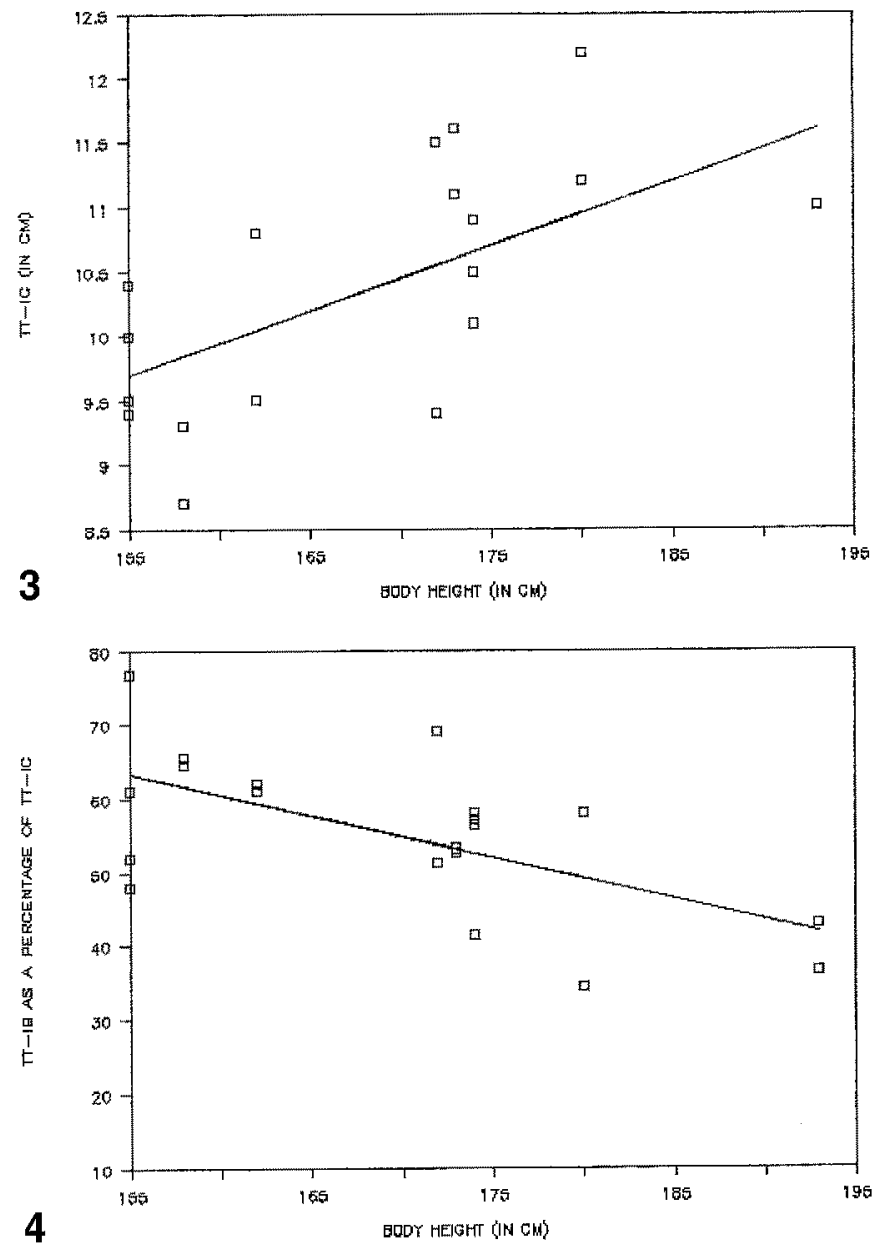

Figs. 3, 4

3 Relation between TT-IC (in $\mathrm{cm}$ ) and body height (in $\mathrm{cm}$ ) at incision line ( $\mathrm{p}=0.002$; $\mathrm{r}=0.644$ ). 4 Relation between TT-IB (as a percentage of TT-IC) and body height (in $\mathrm{cm}$ ) at incision line $(\mathrm{p}=0.003 ; \mathrm{r}=-0.624)$

3 Relation entre la ligne antérieure joignant sommet du trochanter et crête iliaque en em et la hauteur du sujet en $\mathrm{cm}$ au niveau de la ligne d'incision $(p=0,002 ; r=0,644) .4$ Relation entre la distance sommet du grand trochanter - branche inférieure (exprimée en \% de la distance sommet du grand trochanter - crête iliaque) et la taille $(e n \mathrm{~cm}$ ) au niveau de la ligne d'incision $(p=0,003 ; r=-0,624)$

No significant differences were found between left and right side nor between sexes.

\section{Influence of body height}

With increasing height, the distance TT-IC significantly increased (Fig. 3), whereas TT-MIB and TT-IB decreased. Figure 4 shows a significant decrease of TT-IB, expressed as a percentage of TT-IC, with increasing height. (range 178-864), 323 axons in the MIB (range 30-672) and 397 axons in the terminal branch to the tensor (range 238-666).

\section{$C T$}

Figure 5 shows the course of the MIB in relation to TT and iliac crest of the right hip. The position of the nerve closely corresponds to the measurements found during dissection. Note the relation to TT.

\section{Discussion}

Several studies deal with the course of the SGN in relation to TT, the conclusions differ. Jacobs and Buxton [8] describe a so-called safe area of $5 \mathrm{~cm}$, being a zone of $5 \mathrm{~cm}$ wide immediately adjacent to the greater trochanter, where no danger exists to damage the SGN. According to them extra care should be taken in short patients, in whom the branches of the SGN may well be inside this safe area. According to Nazarian et al the inferior neurovascular pedicle is situated at a distance of 3 to $5 \mathrm{~cm}$ above the middle of the upper border of the greater trochanter $[10]$. Baker and Bitounis come to the same conclusion, with the restriction that this is only true anteriorly. Posteriorly the distance ranges from 6 to $8 \mathrm{~cm}$ [2]. Goodman finds a distance of 3 to $6.5 \mathrm{~cm} \mathrm{[6],} \mathrm{while}$ according to Foster and Hunter the distance averages $7.82 \mathrm{~cm}$, ranging from 6.3 to $8.4 \mathrm{~cm}$ [4].

The differences mentioned above can be explained by variation in dissection and measuring techniques, by the small magnitude of the series and by differences in the choice of most inferior branch. In their 20 dissections Jacobs and Buxton detached the origin of the gluteus medius muscle from the outer edge of the iliac crest in order to expose the intermuscular plane between the gluteal muscles [8]. In 

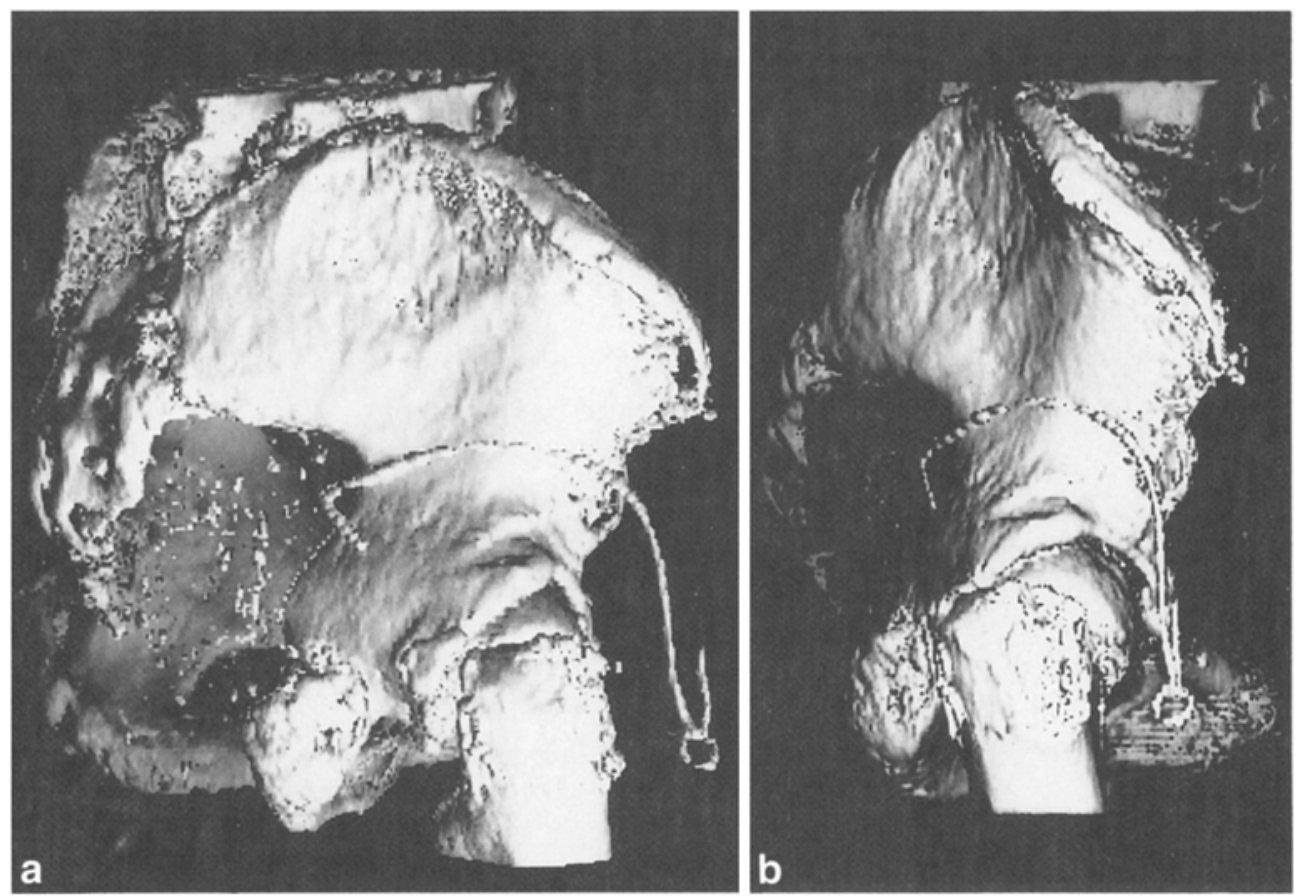

Fig. 5

Three dimensional reconstruction of CT-scan of the right hip with the course of the most inferior branch of the superior gluteal $\mathrm{n}$.

Reconstruction tridimensionnelle au scanner de la hanche droite montrant le trajet de la branche inférieure supplémentaire du n. glutéal supérieur

the 20 dissections of Goodman the tendon of the gluteus medius was cut and the muscle superiorly reflected [6]. Nazarian dissected 32 specimens following a direct lateral approach with detachment of a gluteal bucket-handle flap [10].

With regard to the measuring technique, Jacobs and Buxton used the midlateral line and studied the situation anterior and posterior to this line. They measured the distance from TT to the entry point of all branches into the deep surface of the gluteus medius muscle [8]. Goodman only measured the distance between TT and the most inferior branch, which supplied the gluteus medius or minimus or tensor muscle [6]. By performing a direct lateral approach, Nazarian et al [10], Foster and Hunter [4], and Pascarel et al [11] measured the distance between TT and the inferior branch in the plane of the incision in the gluteus medius muscle. The localisation of this incision varies, however, in different studies. Nazarian et al used an incision equidistant between the anterior and posterior margins of the trochanter. Foster and Hunter as well as Pascarel used the incision of Hardinge, which is posterior through the gluteus medius and anterior through the vastus lateralis muscle. Pascarel et al concluded from 15 dissections that the SGN emerges above the piriformis muscle at a distance of $4.5 \mathrm{~cm}$ superior and $2 \mathrm{~cm}$ posterior to TT.

Jacobs and Buxton distinguish two patterns of nerve distribution:

1. the spray pattern which is the most common, in which the main trunk divides into numerous branches just anterior to the piriformis,

2. the transverse neural-trunk pattern, in which the majority of the branching is more peripheral. Goodman adds in a comment on Jacobs and Buxton that in his study the pattern of branching shows more variation [5].

In our study we found a spray pattern in all limbs with the inferior branch (ramus inferior) being the most inferior one in $35 \%$. In the remaining hips a so-called most inferior branch was found on an average of $1 \mathrm{~cm}$ distal to the inferior branch. When using a more dorsally located incision in the gluteus medius muscle the risk of damaging a nerve branch is less, but if so a major branch is affected. A more anteriorly located incision enlarges the risk of damaging a nerve but a minor branch is affected.

In our study the distance TTMIB ranges from 3.3 to $6.3 \mathrm{~cm}$, the distance TT-IB from 4.0 to $7.3 \mathrm{~cm}$. Consequently, we agree with Goodman that a safe area of $5 \mathrm{~cm}$, as suggested by Jacobs and Buxton, is too permissive.

In all studies referred to above, exclusively the relation of the SGN to TT was determined. In our study the distance from TT to iliac crest was measured as well. We found that at the incision line the distances TT-MIB and TT-IB average $45.0 \%$ and $55.1 \%$ of the distance TT-iliac crest respectively. The IB never reaches the distal one third of the distance TT-iliac crest, the MIB only in one case.

With increasing height TT-IC increases significantly; in contrast, TT-MIB and TT-IB have a tendency to decrease. Consequently, not in 
short but in tall patients extra care should be taken in surgical approaches to the hip. This conclusion is opposite to that of Jacobs and Buxton.

In view of the number of axons the terminal branch to the tensor muscle is a substantial one, comparable with the IB. This finding suggests that this branch of the SGN constitutes the only nerve supply for the tensor. Indeed, in none of the 20 hips branches from the femoral nerve to the tensor were found.

\section{Conclusions}

The inferior branch (ramus inferior) of the SGN is the main trunk of the nerve and the main supply for the gluteus medius muscle. A lesion of this branch will have serious consequences for walking of the patient. In $65 \%$ of the hips a smaller branch (MIB) is found about $1 \mathrm{~cm}$ distal to the inferior branch. This branch is even in more danger. Since the distance to the tip of the greater trochanter ranges from 3.3 to $6.3 \mathrm{~cm}$, proximal extension of the trans-gluteal incision should be limited to $3 \mathrm{~cm}$ proximal to the tip.
Not in all circumstances is the tip of the greater trochanter a good reference point. In cases of severe congenital dysplasia of the hip or severe coxa vara it can be useful to refer to the iliac crest. Then, the transgluteal incision should not be extended beyond the distal one third of the distance TT-iliac crest. Extra care is requested in tall patients, in whom the (most) inferior branch lies more distally.

\section{References}

1. Abitbol JJ, Gendron D, Laurin CA, Beaulieu MA (1990) Gluteal nerve damage following total hip arthroplasty. A prospective analysis. J Arthroplasty 5: 319-322

2. Baker AS, Bitounis VC (1989) Abductor function after total hip replacement: an electromyographic and clinical review. $J$ Bone Joint Surg [Br] 71-B : 47-50

3. Bauer R, Kerschbaumer F, Poisel S, Oberthaler W (1979) The transgluteal approach to the hip joint. Arch Orthop Trauma Surg $95: 47-49$

4. Foster DE, Hunter JR (1987) The direct lateral approach to the hip for arthroplasty. Advantages and complications. Orthopedics $10: 274-280$

5. Goodman SB (1990) Comment. J Bone Joint Surg [Am] 72-A : 791-792
6. Goodman SB (1991) Does the direct lateral approach to the hip joint jeopardize the superior gluteal nerve? Clin Anat $4: 123-128$

7. Hardinge $\mathrm{K}$ (1982) The direct lateral approach to the hip. J Bone Joint Surg [Br] 64-B : 17-19

8. Jacobs LGH, Buxton RA (1989) The course of the superior gluteal nerve in the lateral approach to the hip. J Bone Joint Surg [Am] 71-A : 1239-1243

9. McFarland B, Osborne G (1954) Approach to the hip: a suggested improvement on Kocher's method. J Bone Joint Surg [Br] 36-B : 364 367

10. Nazarian S, Tisserand $\mathrm{Ph}$, Brunet $\mathrm{Ch}$, Müller ME (1987) Anatomic basis of the transgluteal approach to the hip. Surg Radiol Anat $9: 27-35$

11. Pascarel $X$, Dumont $D$, Nehme $B$, Dudreuilh IP, Honton IL (1989) Arthroplastie totale de hanche par voie de Hardinge. Résultat clinique de 63 cas. Revue de Chirurgie Orthopédique 75:98-103

12. Picard JJ, Trink Van Dam (1983) Voie d'accès antéroexterne de la hanche. In traitement du descellement des prothèses totales de hanche. Cinquièmes Journées de Chirurgie de la hanche, Lyon, 2 et 3 décembre

13. Spalteholz-Spanner (1961) Handatlas der Anatomie des Menschen, vol 2, 16th edn. Scheltema \& Holkema, Amsterdam, pp 182-183

Received November 25, 1993 / Accepted in final form February 18, 1994 